\title{
Testing the Vulnerability of the Phylotypic Stage: On Modularity and Evolutionary Conservation
}

Frietson Galis (galis@rulsfb.leidenuniv.nl)

Johan A.J. Metz (metz@rulsfb.leidenuniv.nl)

\section{Approved by}

Ulf Dieckmann (dieckmann@iiasa.ac.at)

Project Leader, Adaptive Dynamics Network

June 2001 


\section{Contents}

Conservation Can be Ascribed to Stabilizing Selection .................................................. 1

Hypothesis to Explain the Stabilizing Selection ........................................................... 1

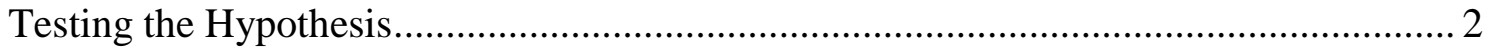

Phylotypic Stage is a Highly Vulnerable Stage …......................................................... 2

Timing of peak mortality in rodent models ............................................................. 2

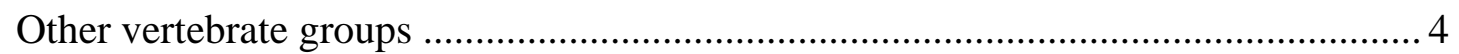

Interactiveness is the Cause of the Vulnerability.......................................................... 4

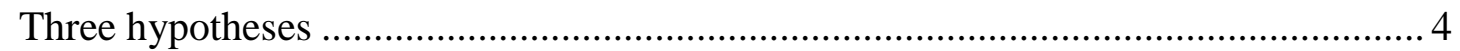

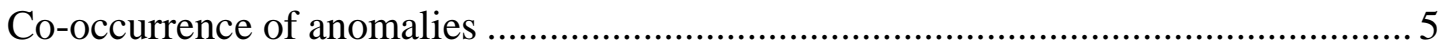

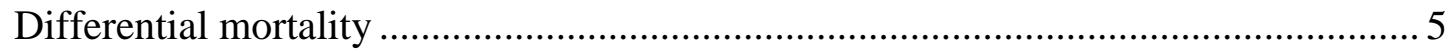

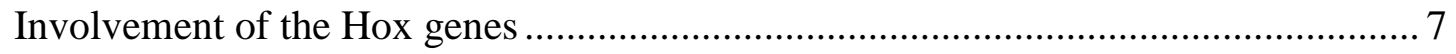

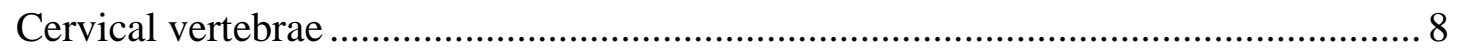

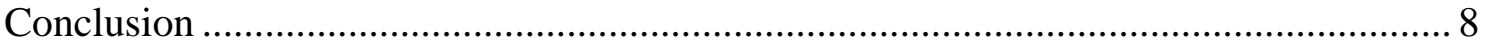

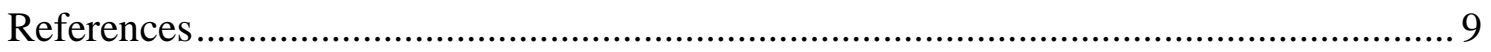




\begin{abstract}
The phylotypic stage is the developmental stage at which vertebrates most resemble each other. In this study we test the plausibility of the hypotheses of Sander (1983) and Raff (1994) that the phylotypic stage is conserved due to the intense and global interactivity occurring during that stage. First, we test the prediction that the phylotypic stage is much more vulnerable than any other stage. A search of the teratological literature shows that disturbances at this stage lead to a much higher mortality than in other stages, in accordance with the prediction. Second, we test whether that vulnerability is indeed caused by the interactiveness and lack of modularity of the inductions or, alternatively, is caused by some particularly vulnerable process going on at that time. From the pattern of multiple induced anomalies we conclude that it is indeed the interactiveness that is the root cause of the vulnerability. Together these results support the hypotheses of Sander and Raff. We end by presenting an argument on why the absence of modularity in the inductive interactions may also be the root cause of the conservation of the much discussed temporal and spatial colinearity of the H ox genes.
\end{abstract}




\author{
About the Authors \\ Frietson Galis \\ Institute of Evolutionary and Ecological Sciences (EEW) \\ Section Theoretical Evolutionary Biology \\ Leiden University \\ 2311 GP Leiden, The Netherlands \\ Johan A.J. Metz \\ Institute of Evolutionary and Ecological Sciences (EEW) \\ Section Theoretical Evolutionary Biology \\ Leiden University \\ 2311 GP Leiden, The Netherlands \\ and \\ Adaptive Dynamics Network \\ International Institute for Applied Systems Analysis \\ A-2361 Laxenburg, Austria
}

\title{
Acknowledgments
}

We thank Jacques van Alphen, Elisabeth van Ast-Gray, Pete Chabora, Roberta Koepfer, Allen Herre, Russ Lande, Mike Richardson, Urs Schmidt-Ott, and Matthias Starck for helpful discussions and comments on the manuscript. We thank Martin Brittijn for help with the figures. 


\title{
Testing the Vulnerability of the Phylotypic Stage: On Modularity and Evolutionary Conservation
}

\author{
Frietson Galis
}

Johan A.J. Metz

The mechanisms responsible for the remarkable conservation of the vertebrate phylotypic stage are poorly understood. This is the stage of maximum similarity of the body plans of the various vertebrates (e.g., Medawar, 1954; Seidel, 1960; Ballard, 1981; Sander, 1983; Gilbert, 1997; Wolpert et al., 1998; Hall, 1997, 1999). It starts approximately with neurulation and ends when most of the somites have been formed. The similarity can only be explained by an evolutionary conservation in all vertebrate classes. (Hall, 1997) It was first noted by Von Baer (1828) and turned into dogma by Haeckel (1874). Haeckel even claimed that these stages are nearly identical among vertebrates. To support his claim he went as far as modifying drawings (Richardson et al., 1997; see also Goldschmidt, 1956). However, the recent exposition of Haeckel's massaging of the data should not distract us from the fundamental importance for evolutionary theory of explaining the strong constraint on evolutionary change that has kept the phylotypic stage so similar among the vertebrates.

\section{Conservation Can be Ascribed to Stabilizing Selection}

When morphological patterns are conserved, this is either because there is no production of genetic variation for the pattern or because they are understrong stabilizing selection, i.e., stabilizing selection against changes in almost any direction under almost all environmental conditions. For the phylotypic stage in vertebrates there is no lack of intraspecific genetic variation. For instance, numerous anomalies of neural tube closure with a genetic basis exist in mammalian species (e.g., Van Allen et al., 1993; Hume et al., 1996). There is also intraspecific variation in the number of somites which can be deduced from the intraspecific variation in the number of vertebrae that arise from them at a later stage of development (Schulz, 1961; Woolfenden, 1961). Therefore, the conservation has to be the result of strong stabilizing selection against mutational changes during this stage.

\section{Hypothesis to Explain the Stabilizing Selection}

Raff (1994, 1996) has proposed the following hypothesis to explain the strong selection against evolutionary changes during the phylotypic stage: The web of intense interactions among organ primordial (somites, neural tube, chorda) of the embryo at this stage causes any small mutational change to lead to many pleiotropic effects elsewhere in the embryo, thus reducing the chance of a favourable mutation. At earlier stages there are fewer inductive interactions as there are no organ primordial yet. At later stages 
there are many more inductive interactions, but they take place within semi-independent modules (e.g., limbs). Sander (1983), who first introduced the term "phylotypic stage" as an alternative to the terms Körpergrundgestalt of Seidel (1960) and phyletic stage of Cohen (1977), already proposed a more abstract version of this hypothesis: the evolutionary conservation of the phylotypic stage is caused by pleiotropic effects resulting from interactions between developmental modules. He also already points to the fact that the stages preceding the phylotypic stage are highly variable, but that thereafter the developmental pathways converge (see also Seidel, 1960).

The hypotheses of Sander and Raff are in agreement with current ideas on the importance of modularity (the existence of semi-independent units within organisms) as a condition for evolutionary change (e.g., Bonner, 1988; Galis, 1996; Wagner, 1996). Developmental modularity limits the effects of mutational changes to only part of the organism, thereby greatly reducing the probability that advantageous changes are associated with adverse effects elsewhere. It is thus the lack of modularity that is hypothesized to be the cause of the evolutionary conservation of the phylotypic stage.

\section{Testing the Hypothesis}

Although it is not possible to test this hypothesis on the evolutionary past directly, we can certainly test it indirectly. We reason that if the lack of modularity constrains evolutionary change at this stage, then artificially induced changes during this stage should have many negative effects throughout the body. Therefore, we predict that the phylotypic stage is more vulnerable to induced changes than are stages that come before or after it. To test this prediction we performed a literature search for data on sensitive periods for teratogenesis. Only data for mice, rats, and hamsters were found of sufficient quality to justify a detailed analysis. From this literature we selected experiments in which mortality and/or developmental anomalies were scored after subjecting females to single treatments on different days of gestation. (Typically, preliminary experiments were carried out with treatments to allow narrowing of the investigated time window during pregnancy to the period of maximum sensitivity. This was done in order to limit the number of experimental animals that had to be killed in the experiments). We excluded experiments where females died from the treatment, as this would confound detection of direct effects of the timing of a treatment on the embryo or fetus. For each of the remaining experiments we determined the day of peak sensitivity for the induction of mortality, and/or scored the occurrence of various anomalies, calling the day of the setting of the seminal plug gestation day 0 . Below we discuss how these data bear on different aspects of Sander's and Raff's hypotheses. In addition, we briefly discuss how the additional mortality data that we gleaned for other vertebrate groups fit in with the lessons learnt from the rodent data.

\section{Phylotypic Stage is a Highly Vulnerable Stage}

\section{Timing of peak mortality in rodent models}

Figure 1 gives a summary of the results on mortality. Our prediction comes out remarkably well: induction of mortality always strongly peaks during the phylotypic stage [which starts on average on gestation day 6 in hamsters, day 7 in mice, and day 8 in rats and ends with the pharyngula stage on average on gestation day 9 in hamsters, 

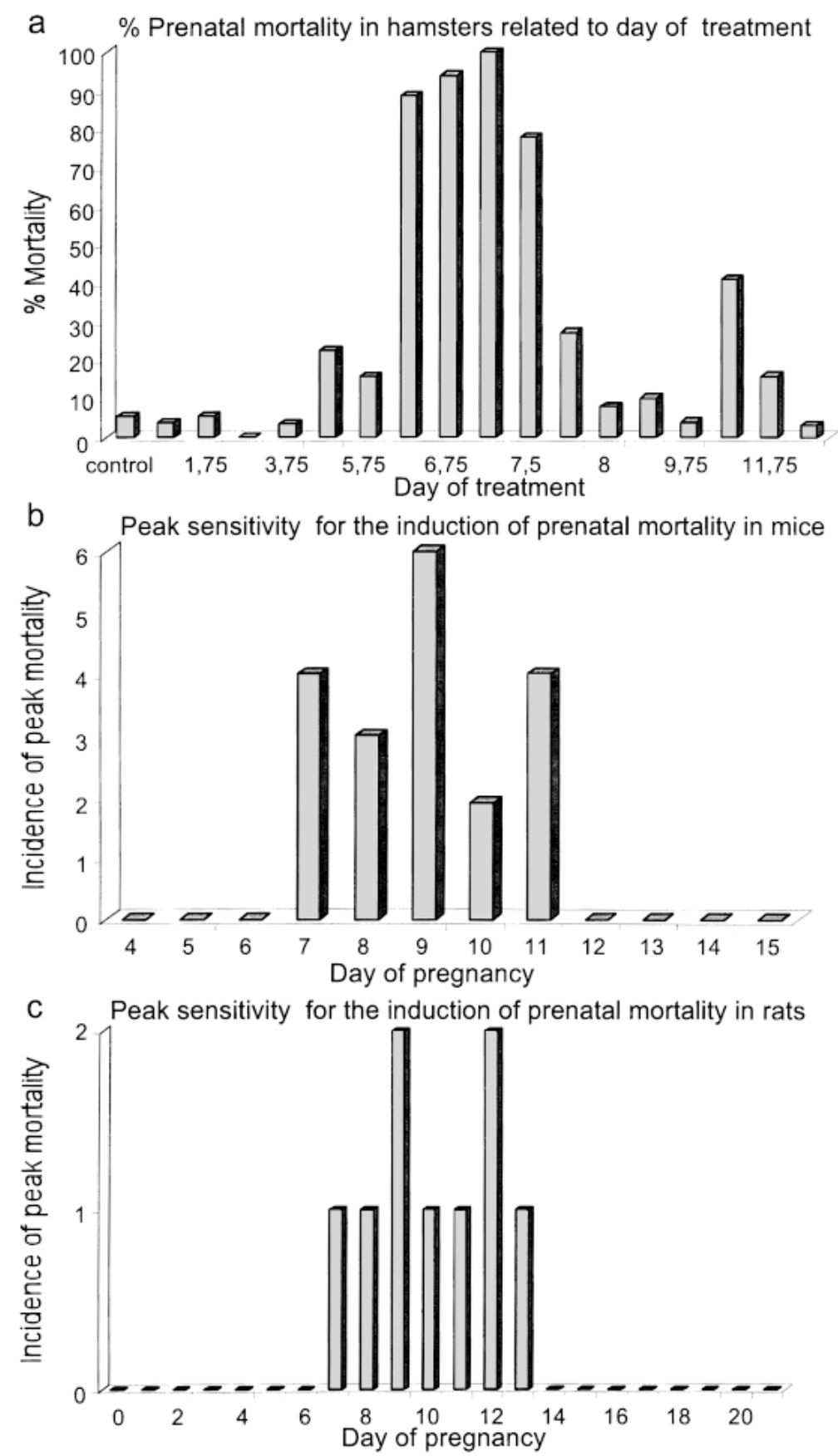

Fig. 1. The vulnerability to teratogenic treatments in rodents is highest during the phylotypic stage [gestation day (gd) 6-9 in hamsters; gd 7-11 in mice; and gd 8-13 in rats (see text)]. a: Frequency diagram showing the percent mortality of hamsters in response to treatment with sodium retinate on a single day during the pregnancy. Peak sensitivity to the induction of mortality is on gestation day 7 (Shenefelt '72). b: Diagram of the teratogenic studies on mice from Table 1 showing the frequency of the peak sensitivity to the induction of mortality during pregnancy. Peak sensitivity was always within the period of gd 7-11 and most often gd 9. c: Diagram of teratogenic studies on rats from Table 1 showing the frequency of the peak sensitivity to the induction of mortality during pregnancy. Peak sensitivity was always within the period of gd 7-13.

day 11 in mice, and day 13 in rats; however, the timing varies considerably among strains (Shenefelt, 1972; Schneider and Norton, 1979; Theiler, 1989; Fujinaga and Baden, 1992)]. In rats the onset is slightly earlier than the start of neurulation on day 7. However, it has to be kept in mind that there is often a delay of several hours between the treatment and the time the teratogen reaches the embryo and that the teratogen can 
persist for up to $24 \mathrm{hr}$ in the embryo (Shenefelt, 1972; Tagashira et al., 1981; Payan et al., 1995; Rogers and Mole, 1997; Kuno et al., 1999; Abu-Qare et al., 2000). Mortality is not limited to this sensitive window, but it is always by far the highest in this period. Clearly, these results corroborate the idea that the phylotypic stage is vulnerable in the extreme.

\section{Other vertebrate groups}

For chickens we found only one experiment where mortality was measured during the entire period of embryogenesis (Landauer and Bliss, 1946). In chickens the phylotypic stage starts approximately at $18 \mathrm{hr}$ after incubation and ends on day 4 (Schneider and Norton, 1979). The mortality response to insulin is highest for treatments at $48 \mathrm{hr}$ after incubation, in the middle of the phylotypic stage. We did not find any suitable data for reptiles or amphibians, except for the observation of Woskressensky (1928) that susceptibility to $\mathrm{X}$ radiation in Axolotls is highest during (and before) fertilization and then decreases to increase again during the phylotypic stage and during hatching. For fishes we found two experiments, both measuring vulnerability to radiation in the killifish F und u lu s he te r o c litu s: a study by Hinrichs (1925) using UV radiation and one by Solberg (1938) using $X$ radiation. In $F$, heteroclitus the phylotypic stage lasts approximately from 23 to $75 \mathrm{hr}$ (Solberg, 1938). In both studies mortality was highest for treatments during fertilization, sharply declining during cleavage to virtually zero, and staying low during gastrulation. Around $22 \mathrm{hr}$, just before the beginning of the phylotypic stage, the induction of mortality increases again and peaks at 34 and $36 \mathrm{hr}$, respectively, to decrease again to around zero before the end of the phylotypic stage. Finally, Woskressensky (1928) notes that in D rosophila susceptibility to X radiation is highest during pupation. Pupation is akin to the phylotypic stage in that the imaginal disks are sites of intense, within-disk, global interactions. From their data on F un $d$ u lu s , Axolotls, and D rosophila, Woskressensky (1928) and Solberg (1938) conclude that susceptibility to $\mathrm{X}$ radiation is closely correlated to the rate of cell division with deviations during the phylotypic stage, hatching, and pupation. Clearly more data are necessary for a firm conclusion. However, the various absolute and local peaks of mortality induced during the phylotypic stage are well in accordance with the idea that the phylotypic stage owes its conservation to its high vulnerability.

\section{Interactiveness is the Cause of the Vulnerability}

\section{Three hypotheses}

Three hypotheses can explain the observed vulnerability of the phylotypic stage in response to disturbances: (a) the many ongoing interactions during the phylotypic stage and the lack of modularity lead to a potentially lethal co-occurrence of anomalies; (b) the increased mortality is caused by the occurrence of a single very sensitive process during the phylotypic stage (for instance, the closure of the neural tube is a very sensitive process (Shenefelt, 1972; Sadler, 1980; Stein et al., 1982) that by itself could cause the vulnerability); (c) the increased mortality is caused by multiple independent anomalies. To distinguish between the three hypotheses we analysed the co-occurrence of anomalies in the selected teratological experiments and differential mortality patterns. 


\section{Co-occurrence of anomalies}

The results of our literature study are summarized in Table 1 and illustrated in Fig. 2a. The results clearly falsify hypothesis $b$ (a single sensitive process causes the vulnerability). In all studies in Table 1 the teratological treatment was associated with multiple anomalies in the surviving fetuses, in particular when it is given on the most sensitive day for the induction of mortality. These anomalies included neural tube defects, vertebral abnormalities, head malformations, genitourinary malformations, eye abnormalities, cleft lip, cleft palate, and cardio-vascular anomalies. The types of the induced anomalies appear to be mainly influenced by the timing rather than by the nature of the teratological treatment (Wilson, 1965; Lu et al., 1979; Sadler, 1980; Lu, 1991; DeSesso and Harris, 1996; see also Opitz, 1985; Lubinsky, 1985, on the associations of malformations as a result of causally nonspecific disruptive effects on developmental fields). In particular, failure of the neural tube to close (e.g., in exencephaly, anencephaly, and myelomeningocele) is usually associated with cranofacial, urogenital, and severe axial skeletal malformations in rodents and humans (e.g., Tori and Dickson, 1980; Martínez-Lage et al., 1996; Padmanabhan and Ahmed, 1996; for further data on covariation see, e.g., Degenhardt, 1954; Shenefelt, 1972; Matschke and Fagerstone, 1977; Slavkin, 1993; Opitz and Gilbert, 1993). Further corroboration can be found in a large survey of 381 teratological studies by Khera (1984) who found that most of the congenital defects in mice are caused by treatment on day 8,9 , or 10 , right in the middle of the phylotypic stage (see for similar results on rats Wilson, 1965).

\section{Differential mortality}

As a means of distinguishing between hypotheses a and $\mathrm{c}$ we considered the differential mortality of fetuses with anomalies. We found that not only serious abnormalities such as exencephaly significantly were over-represented in dead fetuses (Shenefelt, 1972) but also minor anomalies with only a local effect on the fetus such as a cleft lip (Fig. 2; Walker and Crain, 1959; Smithberg and Dixit, 1982; Juriloff and Harris, 1985; Nakane and Kameyama, 1983) and a short tail (Dostal and Jelinek, 1979). The presence of an anomaly with a small local effect cannot increase mortality by itself (see control experiment in Fig. 2b). Therefore, the differential mortality must be due to an association of the minor anomaly with more serious ones. Independence of anomalies (hypothesis c) would lead to the same incidence of cleft lip anomalies in living and dead embryos. The dependency of the anomalies can be due to the interactiveness of inductions or due to a single inductive cascade. Data in the extensive literature on signalling pathways of the phylotypic stage clearly point towards inductive interactiveness as the cause of the dependency of anomalies; there are numerous feedback loops of signals between notochord, neural tube, somites, limbs (in amniotes), and other organ primordia (e.g., Šošić et al., 1997; Marcelle et al., 1997; Mauch et al., 2000). There is no single signalling cascade described that can account for the multitude of associated anomalies that result from disturbances during the phylotypic stage. The dependency of the anomalies, thus, can be taken as support for Sander's and Raff's hypotheses that the interactiveness during the phylotypic stage causes its vulnerability. As an aside we wish to point out that these findings also argue against Richardson's idea (1999) that modifiability during the period of organogenesis (which includes the 
Table 1. Teratoligical studies in which critical periods for the induction of prenatal mortality were determined. Peak day is the day of maximum susceptibility to the induction of mortality. Under abnormalities the different types of abnormalities are listed that were found in the surviving fetuses of treatments in the period of maximum susceptibility to the induction of mortality.

\begin{tabular}{|c|c|c|c|c|}
\hline Teratogenic agent & Strain & Abnormalities ${ }^{a}$ & Peak day & Refer ence \\
\hline \multicolumn{5}{|l|}{ Mice } \\
\hline Adenine & ICR-JCL & $3,4,5$ & 9 & F uji et al., '70 \\
\hline Vigabatrin & TO & $1,2,3,5,9,10$ & 11 & A bdurazzaq et al., '97 \\
\hline Sodium valproate & TO & $1,2,3,10$ & 9 & Padhamanabhan et al., '96 \\
\hline Methanol & CD-1 & $1,2,4,10$ & 7 & Rogers et al., '97 \\
\hline Cadmium chloride & SWV & $1,3,5,6,8$ & 8 & Hovland et al., '99 \\
\hline Cadmium chloride & C 57B L /6N cr IB R & $1,3,5,6,8$ & 7 & Hovland et al., '99 \\
\hline all-trans-R etinic acid & ICR & 14 & 7 & K uno et al., '99 \\
\hline Sodium arsenite & CD-1 & $1,2,7$ & 9 & Baxley et al., '81 \\
\hline Hypoxia & $\mathrm{ddN}$ & $3,5,10,11$ & 10 & Murakami et al., '63 \\
\hline X-ray & $\mathrm{ddN}$ & 3,13 & 9 & Murakami et al., '64 \\
\hline X-ray & C57B L xNB & $1,2,3,5,6,7,12$ & 10 & Russell, '50 \\
\hline Deoxycofor mycin & CD-1 (ICR) & 1,2 & 7 & Knudsen et al., '92 \\
\hline Deoxyadenosine & $C D-1$ & 1,9 & 8 & Gao et al., '94 \\
\hline Dichlor oacetate & $\mathrm{JCl}-\mathrm{ICR}$ & 1,4 & 8 & Sonoda et al., '93 \\
\hline E thanol + aspirin & C57 & $4,5,10$ & 11 & Padhamanabhan et al., '94 \\
\hline 6-Azauridine & Albino & $4,5,10,11$ & 9 & Dostal et al., '79 \\
\hline Lithium & $\mathrm{A} / \mathrm{J}$ & 3,10 & 9 & Smithberg et al., '82 \\
\hline Triamcinelone acetonide & C57B L /6J & 2,10 & 11 & K usanagi, '84 \\
\hline Thyroxine & AMySn & 4,10 & 11 & Juriloff et al., '85 \\
\hline Phosphonacetyl-c-aspartic acid & Swiss albino & $3,4,6,9,10,11$ & 8 & Sieber et al., '80 \\
\hline \multicolumn{5}{|l|}{ Rats } \\
\hline Deficiency pteroyl-glutamic acid & L ong-E vans & 1,13 & 9 & Nelson et al., '55 \\
\hline Ochratoxin & Blue Spruce & $5,6,7$ & 7 & Mayura et al., ' 82 \\
\hline Nitrofen & L ong-E vans & $1,4,6$ & 10 & Costlow et al., '81 \\
\hline B oric acid & Fischer-34 & $2,3,7,9$ & 8 & Narotsky et al., '97 \\
\hline Retinoic acid & Fu-albino & $1,2,3$ & 9 & K istler, '81 \\
\hline Nitrous oxide & Sprague-Dawley & $1,3,4,9$ & 11 & F ujinaga et al., '89 \\
\hline $\mathrm{N}$-Phenylimide & Crd:cj & $3,4,11$ & 12 & Kawamura et al., '95 \\
\hline Almokalant & Sprague-Dawley & $4,5,9,10,11$ & 12 & Webster et al., '96 \\
\hline Dofetilide & Sprague-Dawley & $4,5,10$ & 13 & Webster et al., 96 \\
\hline
\end{tabular}

${ }^{a}$ Abnormalities: 1, neural; 2, facial; 3, vertebral; 4, cardiovascular; 5, limb; 6, urogenital; 7, eye; 8, ear; 9, body wall; 10, cleft lip/palate; 11, lung; 12, gastro-intestinal; 13, unspecified multiple congential anomalies; 14, shift in $\mathrm{H}$ ox gene expression.

phylotypic stage and also stages after it) should provide extra opportunities for evolutionary change. The data show that changes during the phylotypic stage usually lead to multiple abnormalities, i.e., pleiotropic effects in the case of mutational changes. We agree with Richardson (1999) that mutational changes during the phylotypic stage have a large phenotypic effect. However, because this large effect includes many pleiotropic ones, the large phenotypic impact will generally constrain rather than facilitate evolutionary change: a particular potentially useful change during the phylotypic stage almost always will induce lethality even before the organism is exposed to ecological selection and, therefore, will have little chance to end up in a reproductively superior organism once that hurdle is overcome.

Further support for Sander's and Raff's hypotheses comes from differential mortality in human fetuses with cervical ribs (a rib on the 7th cervical vertebra), an anomaly which on its own has only a minor detrimental effect on later survival. In fetuses from stillbirths the frequency of a cervical rib (or rib anlage) is very high, approximately $40 \%$ versus $0.2 \%$ in the general population (McNally et al., 1990, and references in Galis, 1999a). The commitment to make a rib is established in vertebrae early during the phylotypic stage (Kieny et al., 1972; Kant and Goldstein, 1999). This is also the sensitive period for the induction of cervical ribs (Fujinaga et al., 1989; Rogers and Mole, 1997; Narotsky et al., 1998). The presence of a cervical rib, or rib Anlage, just as a cleft lip, cannot be the cause of death and must thus be associated with more serious abnormalities. The exceedingly high incidence of cervical ribs in stillbirths again 


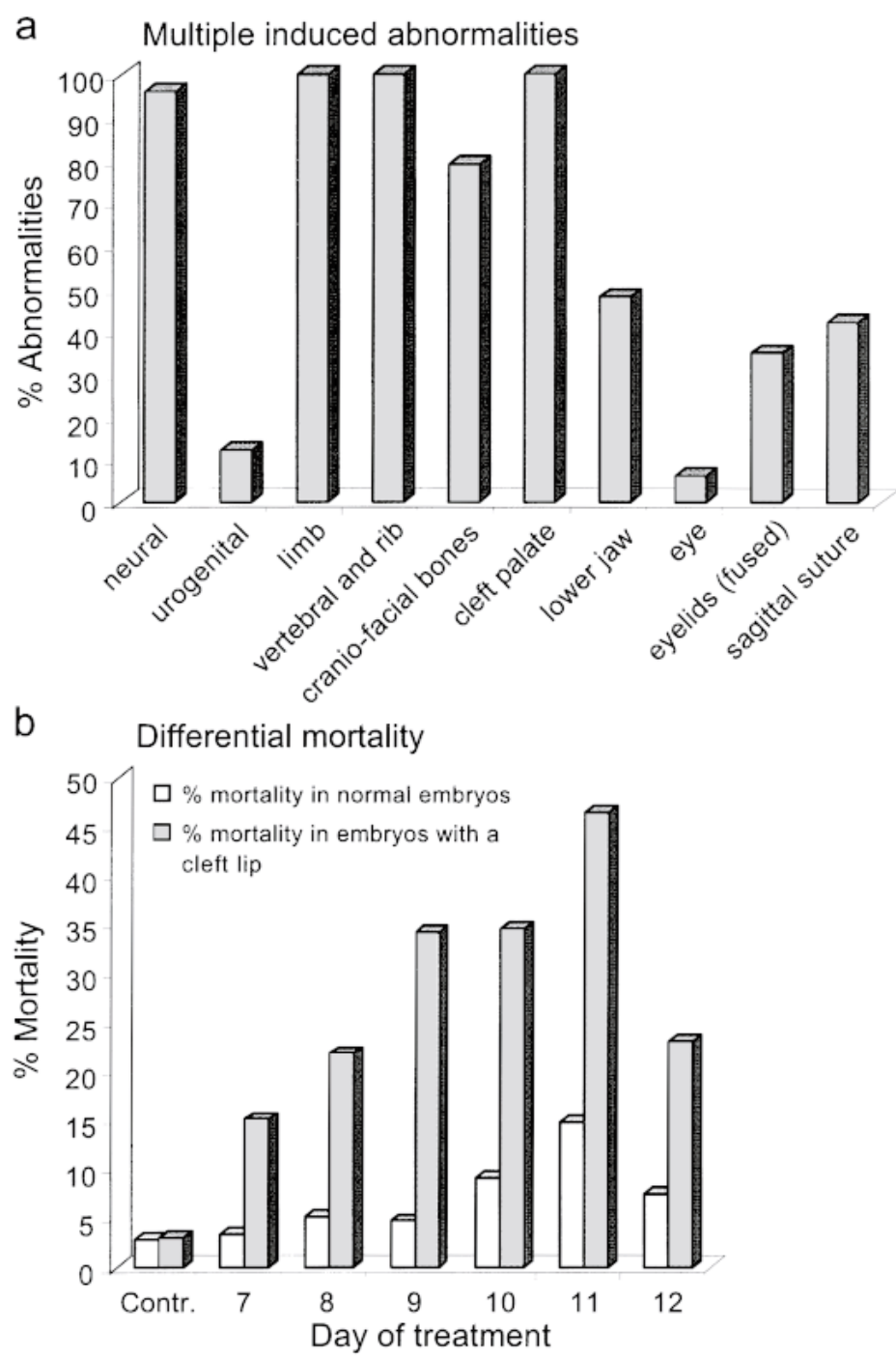

Fig. 2. Teratogenic treatments during the phylotypic stage cause correlated sets of abnormalities. a: Graph showing the percentage of abnormalities in response to treatment with 6aminonicotinamide during the phylotypic stage in mice (Matschke and Fagerstone, '77). It can be deduced from the very high percentages for five different abnormalities that most surviving mice/rat fetuses had a set of at least 5 abnormalities. b: Percentage differential mortality of mice with a

cleft lip calculated from the data of Juriloff and Harris ('85). The control data (no treatment) show that the possession of a cleft lip does not increase mortality. In mice treated with thyroxine, mortality is greatly increased in fetuses with a cleft lip compared to those without. The occurrence of a cleft lip has, thus, to be associated with more serious abnormalities that do cause death.

corroborates the importance of the interactiveness as cause for the vulnerability of the phylotypic stage.

\section{Involvement of the Hox genes}

Slack et al. (1993) made the intriguing observation that the most conserved developmental stage within vertebrates is also the stage during which the $H 0 x$ genes are sequentially activated in the order that they have in the $H o x$ cluster on the chromosomes (temporal and spatial colinearity). Comparison with other taxa suggests that this sequential gene expression is a highly conserved plesiomorph character (McGinnis and Krumlauf, 1992; Kourakis et al., 1997; Brooke et al., 1998). Duboule (1994) hypothesized that the nature of the precise regulation of $H o x$ genes is the cause of the conservation of the phylotypic stage. This statement allows two interpretations: (i) due 
to the colinearity no variation can be produced (no zygotes bearing such variation can be made), or (ii) any variation that is produced is selected against as a direct result of a malregulation within the $H o x$ cluster, i.e., such malregulation necessarily translates into malfunctioning phenotypes independent of how it is embedded in the developmental process. The conservation of the phylotypic stage would then be the indirect consequence of mechanism (i) or (ii) for the conservation of the $H x x$ organisation. However, we know that visible variation due to changes in the $H$ ox genes occurs, even though these variations generally turn out to be inviable due to a malfunctioning of the embryo (not a malfunctioning of the genetic regulation system per se). Moreover, in the meantime evidence has accumulated that the temporal and spatial activation of $H$ ox gene expression at other stages coincides less well with the order of the genes on the chromosomes. Important deviations from colinearity have evolved during hematopoiesis, limb, and skin development (e.g., Rogina et al., 1992; Gardiner, 1995; Nelson et al., 1996; Rijli and Chambon, 1997; Godwin and Capecci, 1998). For instance, in the skin some $H \circ x$ genes are globally expressed whereas others are regionally restricted (Godwin and Capecci, 1998). Apparently, keeping the $H$ ox gene regulation well organised matters less than the specific moment at which this should be the case.

Therefore we conclude that the selective mechanism behind the conservation of colinearity should primarily be sought in the high interactiveness during the phylotypic stage. This, and not the $H O x$ organisation itself, causes changes in the $H o x$ organization to have multiple and therefore major and detrimental phenotypic effects. This argument places the general interactiveness of the phylotypic stage at the root of the conservation of the $H_{0 X}$ organization, rather than placing the tight regulation of the $H o x$ gene expression per se at the root of the conservation of the phylotypic stage.

\section{Cervical vertebrae}

Interestingly, a coupling of $H \propto x$ gene functions during the phylotypic stage also plays a role in another famous example of conservation, the number of cervical vertebrae in mammals. Galis (1999a) argued that the cause of this constraint should be sought in negative pleiotropic effects of $H O x$ genes, with changes in the number of cervical vertebrae leading to an increased susceptibility to cancer and stillbirths. In a general sense the inability of evolution to decouple the $H \circ x$ gene functions in proliferation and patterning was hypothesized by Galis (1999b) to be caused by a lack of modularity analogous to the one underlying the conservation of the phylotypic stage as a whole.

\section{Conclusion}

We conclude that our results support the hypothesis that the phylotypic stage is a highly vulnerable one because of the absence of modularity in the inductive interactions during this stage. This conclusion supports the hypotheses of Sander (1983) and Raff (1994, 1996) that the conservation of the phylotypic stage is caused by the high number of ongoing interactions. Finally, we argue that this temporally restricted absence of modularity also is the ultimate reason for the conservation of the temporal and spatial colinearity of the $H \circ x$ genes. 


\section{References}

Abdulrazzaq YM, Bastaki SMA, Padmanabhan R. 1997. Teratogenic effects of Vigabatrin in mouse fetuses. Teratology 55:165-176.

Abu-Qare, AW, Abdel-Rahman, AA, Kishk, AM, Abou-Donia, MB. 2000. Placental transfer and pharmacokinetics of a single dermal dose of [C-14]methyl parathion in rats. Toxicol Sci 53:5-12.

Ballard, WW. 1981. Morphogenetic movements and fate maps of vertebrates. Amer Zool 21:391-399.

Baxley MN, Hood RD, Vedel GC, Harrison WC, Szczech GM. 1981. Prenatal toxicity of orally administered sodium arsenite in mice. Bull Environ Contam Toxicol 26:749-756.

Bonner JT. 1988. The evolution of complexity. Princeton, NJ: Princeton University Press.

Brooke NM, Garcia-Fernandez J, Holland PWH. 1998. The $P$ a r a H o $x$ gene cluster is an evolutionary sister of the $H o x$ gene cluster. Nature 392:920-922.

Cohen J. 1977. Reproduction. London: Butterworth.

Costlow D, Manson JM. 1981. The heart and diaphragm: target organs in the neonatal death induced by Nitrofen (2,3- dichlorophenyl-p -nitrophenyl ether). Toxicology 20:209-227.

De Sesso JM, Harris SB. 1996. Principles underlying developmental toxicity. In: Fan AM, Chang LW, editors. Toxicology and risk assessment principles, methods, and applications. New York: Marcel Dekker. p 37-56.

Degenhardt K-H. 1954. Durch $\mathrm{O}_{2}$-Mangel induzierte Fehlbildungen der Axialgradienten bei Kaninchen. Z Naturforsch 9b:530-536.

Dostal M, Jelinek R. 1979. Embryotoxicity of transplacentally and intraamniotically administered 6-azauridine in mice. Teratology:143-148.

Duboule D. 1994. Temporal colinearity and the phylogenetic progression: a basis for the stability of the vertebrate Bauplan and the evolution of morphologies through heterochrony. Development (Suppl) 135-142.

Fujii T. 1970. Relation between embryotoxicity of adenine in mice and day of prenatal treatment. Teratology 3:299-310.

Fujinaga M, Baden JM, Mazze RI. 1989. Susceptible period of nitrous oxide teratogenicity in Sprague-Dawley Rats. Teratology 40:439-444.

Fujinaga M, Baden JM. 1992. Variation in development of rat embryos at the presomite period. Teratology 45:661-670.

Galis F. 1996. The application of functional morphology to evolutionary studies. Trends Ecol Evol 11:124-129. 
Galis F. 1999a. Why do almost all mammals have seven cervical vertebrae? Developmental constraints, $H$ ox genes and cancer. J Exp Zool (Mol Dev Evol) 285:19-26.

Galis F. 1999b. On the homology of structures and Hox genes: the vertebral column. Novartis Found Symp 222:80-94.

Gao X, Blackburn MR, Knudsen TB. 1994. Activation of apoptosis in early mouse embryos by 2'-deoxyadenosine exposure. Teratology 49:1-12.

Gardiner DM, Blumberg B, Komine Y, Bryant SV. 1995. Regulation of HoxA expression in developing and regenerating axolotl limbs. Development 121:17311741.

Gilbert SF. 1997. Developmental biology, 5th edition. Sunderland, MA: Sinauer Associates.

Godwin AR, Capecchi MR. 1998. Hoxc13 mutant mice lack external hair. Genes Dev 12:465-476.

Goldschmidt RB. 1956. The golden age of zoology: portraits from memory. Seattle: University of Washington Press.

Haeckel E. 1874. Anthropogenie oder Entwicklungsgeschichte des Menschen. Leipzig: Engelmann.

Hall BK. 1997. Phylotypic stage or phantom: is there a highly conserved embryonic stage in vertebrates? Trends Ecol Evol 12:461-463.

Hall BK. 1999. Evolutionary developmental biology, 2nd edition. Dordrecht: Kluwer Academic Press.

Hinrichs MA. 1925. Modification of development on the basis of differential susceptibility to radiation. I. Fundulus heteroclitus and ultra-violet radiation. J Morphol Physiol 41:239-265.

Hovland DN Jr, Machado AF, Scott WJ Jr, Collins MD. 1999. Differential sensitivity of the SWV and C57BL/6 Mouse strains to the teratogenic action of single administrations of cadmium given throughout the period of anterior neuropore closure. Teratology 60:13-21.

Hume RF, Drugan A, Reichler, A Lampinen J, Martin LS, Johson MP, Evans MI. 1996. Aneuploidy among prenatally detected neural tube defects. Am J Med Genet 61:171-173.

Juriloff DM, Harris MJ. 1985. Thyroxine-induced differential mortality of cleft lip mouse embryos: dose- and time- response studies of the A/WySn strain. Teratology 31: 319-329.

Kant RS, Goldstein R. 1999. Plasticity of axial identity among somites: cranial somites can generate vertebrae without expressing Hox genes appropriate to the trunk. Dev Biol 216: 507-520.

Kawamura S, Kato T, Matsuo M, Sasaki M, Katsuda Y, Hoberman AM, Yasuda M. 1995. Species difference in developmental toxicity of an $N$-phenylimide herbicide between rats and rabbits and sensitive period of the toxicity to rat embryos. Congr Anom 35:123-132. 
Khera KS. 1984. Maternal toxicity-a possible factor in fetal malformations in mice. Teratology 29:411-416.

Kieny M, Mauger A, Sengel P. 1972. Early regionalization of the somitic mesoderm as studied by the development of the axial skeleton of the chick embryo. Dev Biol 28:142-161.

Kistler A. 1981. Teratogenesis of retinoic acid in rats: susceptible stages and suppression of retinoic acid-induced limb malformations by cycloheximide. Teratology 23:25-31.

Knudsen TB, Winters RS, Otey SK, Blackburn MR, Airhart MJ, Church JK, Skalko RG. 1992. Effects of (R)-deoxycoformycin (Pentostatin) on intrauterine nucleoside catabolism and embryo viability in the pregnant mouse. Teratology 45:1-103.

Kourakis MJ, Master VA, Lokhorst DK, Nardelli-Haefliger D, Wedeen CJ, Martindale MQ, Shankland M. 1997. Conserved anterior boundaries of $H A x$ gene expression in the cenetral nervous system of the leech H e lo b d ella . Dev Biol 190:284-300.

Kuno N, Kadomatsu K, Muramatsu T. 1999. Determination of the optimal time and dosage of a ll-trans - retinoic acid for induction of murine exencephaly. Teratology 60:63-67.

Kusanagi T. 1984. Sensitive stages and dose-response analyses of palatal slit and cleft palate in C57BL/6 mice treated with a glucocorticoid. Teratology 29:281-286.

Landauer W, Bliss CI. 1946. Insulin-induced rumplessness of chickens. III. The relationship of dosage and of developmental stage at time of injection to response. J Exp Zool 102:1-22.

Lu CC, Matsumoto N, Iijima S. 1979. Teratogenic effects of nickel chloride on embryonic mice and its transfer to embryonic mice. Teratology 19:137-142.

Lu FC. 1991. Basic toxicology. Fundamentals, target organs and risk assessment. Bristol, PA: Taylor and Francis.

Lubinsky M. 1985. Associations in clinical genetics with a comment on the paper by Evans et al. on tracheal agenesis. Am J Med Genet 21:21-34.

Marcelle C, Stark MR, Bronner-Fraser M. 1997. Coordinate actions of BMPs, Wnts, Shh and Noggin mediate patterning of the dorsal somite. Development 124:39553963.

Martínez-Lage JF, Poza M, Lluch, T. 1996. Craniosynostosis in neural tube defects: a theory on its pathogenesis. Surg Neurol 46:465-470.

Matschke GH, Fagerstone KA. 1977. Teratogenic effects of 6-aminonicotinamide in mice. J Toxicol Environ Health 3: 735-743.

Mauch TJ, Yang G, Wright M, Smith D, Shoenwolf GC. 2000. Signals from trunk paraxial mesoderm induce pronephros formation in chick intermediate medsoderm. Dev Biol 220:62-75.

Mayura K, Reddy RV, Hayes AW, Berndt WO. 1982. Embryocidal, fetotoxic and teratogenic effects of ochratoxin a in rats. Toxicology 25:175-185. 
McGinnis W, Krumlauf R. 1992. Homeobox genes and axial patterning. Cell 68:283302.

McNally E, Sandin B, Wilkins RA. 1990. The ossification of the costal element of the seventh cervical vertebra with particular reference to cervical ribs. J Anat 170:125-129.

Medawar PB. 1954. The significance of inductive relationships in the development of vertebrates. J Embryol Exp Morphol 2:172-174.

Murakami U, Kameyama Y. 1963. Vertebral malformation in the mouse foetus caused by maternal hypoxia during early stages of pregnancy. J Embryol Exp Morphol 11:107-118.

Murakami U, Kameyama Y. 1964. Vertebral malformation in the mouse foetus caused by X-radiation of the mother during pregnancy. J Embryol Exp Morphol 12:841850.

Nakane K, Kameyama Y. 1983. Effect of maternal fasting on the manifestation of cleft lip in CL/Fr mice. Congr Anom 23:207-210.

Narotsky MG, Brownie CF, Kavlock RJ. 1997. Critical period of carbon tetracholorideinduced pregnancy loss in Fischer-344 rats, with insights into the detection of resorption sites by ammonium sulfide staining. Teratology 56:252-261.

Narotsky MG, Schmid JE, Andrews JE, Kavlock RJ. 1998. Effects of boric acid on axial skeletal development in rats. Biol Trace Element Res 66:373-394.

Nelson CE, Morgan BA, Buke AC, Laufer E, DiMambro E, Murtaugh LC, Gonzales E, Tessarrollo L, Parad LF, Tabin C. 1996. Analysis of $H$ ox gene expression in the chick limb bud. Development 122:1449-1466.

Nelson MM, Wright HV, Asling CW, Evans HM. 1955. Multiple congenital abnormalities resulting from transitory deficiency of pteroylglutamic acid during gestation in the rat. J Nutrition 51:349-369.

Opitz JM. 1985. The developmental field concept. Am J Med Genet 21:1-11.

Opitz JM, Gilbert SF. 1993. Developmental field theory and the molecular analysis of morphogenesis: a comment on Dr. Slavkins's observations. Am J Med Genet 47:687-688.

Padmanabhan R, Ahmed I. 1996. Sodium valproate augments spontaneous neural tube defects and axial skeletal malformations into mouse fetuses. Reprod Toxicol 10:345-363.

Padmanabhan R, Hameed MS. 1994. Exencephaly and axial skeletal malformations induced by maternal administration of sodium valproate in the MF1 mouse. $\mathrm{J}$ Craniofac Genet Dev Biol 14:192-205.

Payan JP, Saillenfait AM, Bonnet P, Fabry JP, Langonne I, Sabate JP. 1995. Assessment of the developmental toxicity and placental transfer of 1,2dichloroethane in rats. Fund Appl Toxicol 28:187-198.

Raff RA. 1994. Developmental mechanisms in the evolution of animal form: origins and evolvability of body plans. In: Bengston S, editor. Early life on Earth. New York: Columbia University Press. p 489-500. 
Raff RA. 1996. The shape of life. Chicago: University of Chicago Press.

Richardson MK. 1999. Vertebrate evolution: the developmental origins of adult variation. BioEssays 21:604-613.

Richardson MK, Hanken J, Gooneratne ML, Pieau C, Raynaud A, Selwood L, Wright GM. 1997. There is no highly conserved embryonic stage in the vertebrates: implications for current theories of evolution and development. Anat Embryol 196:91-106.

Rijli FM, Chambon P. 1997. Genetic interactions of $H_{0} x$ genes in limb development: learning from compound mutants. Curr Opinion Genet Dev 7:481-487.

Rogers JM, Mole ML. 1997. Critical periods of sensitivity to the developmental toxicity of inhaled methanol in the CD-1 mouse. Teratology 55:364-372.

Rogina B, Coelho C, Kosher RA, Upholt WB. 1992. The pattern of expression of the chicken homolog of HOX11 in the developing limb suggests a possible role in the ectodermal inhibition of chondrogenesis. Dev Dyn 193:92-101.

Russell LB. 1950. X-ray induced developmental abnormalities in the mouse and their use in the analysis of embryological patterns. J Exp Zool 114:545-602.

Sadler TW. 1980. Effects of maternal diabetes on early embryogenesis: II. Hyperglycemia-induced exencephaly. Teratology 21:349-356.

Sander K. 1983. The evolution of patterning mechanisms: gleanings from insect embryogenesis and spermatogenesis. In: Goodwin BC, Holder N, Wylie CC, editors. Development and evolution. Cambridge: Cambridge University Press. p137-159.

Schneider BF, Norton S. 1979. Equivalent ages in rat, mouse and chick embryos. Teratology 19:273-278.

Schulz AH. 1961. Vertebral column and thorax. In: Hofer H, Schultz AH, Starck D, editors. Primatologia, handbook of primatology. Basel: Karger. p 5/1-5/66.

Seidel F. 1960. Körpergrundgestalt und Keimstruktur. Eine Erörterung über die Grundlagen der vergleichenden und experimentellen Embryologie und deren Gültigkeit by phylogenetischen Überlegungen. Zool Anz 164:245-305.

Shenefelt RE. 1972. Morphogenesis of malformations in hamsters caused by retinoic acid: relation to dose and stage at treatment. Teratology 5:103-118.

Sieber SM, Botkin CC, Soong P, Lee EC, Whang-Peng J. 1980. Embryotoxicity in mice of phosphonacetyl-L-aspartic acid (PALA), a new antitumor agent. I. Embryolethal, teratogenic, and cytogenic effects. Teratology 22:311-319.

Slack JMW, Holland PWH, Graham CF. 1993. The zootype and the phylotypic stage. Nature 361:490-492.

Slavkin HC. 1993. Rieger Syndrome revisited: experimental approaches using pharmacologic and antisense strategies to abrogate EGF and TGF-alpha functions resulting in dysmorphogenesis during embryonic mouse craniofacial morphogenesis. Am J Med Genet 47:689-697. 
Smithberg M, Dixit PK. 1982. Teratogenic effects of lithium in mice. Teratology 26:239-246.

Solberg AN. 1938. The susceptibility of $F$ und u lus heteroc litus embryos to X-radiation. J Exp Zool 78:441-465.

Sonoda T, Ohdo S, Ohba K, Okishima T, Hayakawa K. 1993. Sodium valproateinduced cardiovascular abnormalities in the Jcl:ICR mouse fetus: peak sensitivity of gestational day and dose-dependent effect. Teratology 48:127-132.

Šošić D, Brand-Saberi B, Schmidt C, Christ B, Olson EN. 1997. Regulation of p a r a x is expression and somite formations by ectoerm- and neural tube-derived signals. Dev Biol 185:229-243.

Stein SC, Feldman JG, Freidlander M, Klein RJ. 1982. Is myelomeningocele a disappearing disease? Pediatrics 69:511-514.

Tagashira E, Nakao K, Urano T, Ishikawa S, Hiramori T, Yanaura S. 1981. Correlation of teratogenicity of aspirin to the stage-specific distribution of salicylic acid in rats. Jpn J Pharmacol 31:563-571.

Theiler K. 1989. The house mouse. Atlas of embryonic development. Berlin: Springer Verlag.

Tori JA, Dickson JH. 1980. Association of congenital anomalies of the spine and kidneys. Clin Orthop Related Res 148:259-262.

Van Allen MI, Kalousek DK, Chernoff GF, Juriloff D, Harris M, McGillivray BC, Yong S-L, Macleod PM, Chitayat D, Friedman JM, Wilson RD, McFadden DD, Pantzar J, Ritchie S, Hall JG. 1993. Evidence for multi-site closure of the neural tube in humans. Am J Med Genet 47:723-743.

Von Baer KE. 1828. Entwicklungsgeschichte der Tiere: Beobachtung und Reflexion Königsberg: Bornträger. 264 p.

Wagner GP. 1996. Homologues, natural kinds and the evolution of modularity. Amer Zool 36:36-43.

Walker BE, Crain B. 1959. The lethal effect of cortisone on mouse embryos with sopontaneous cleft lip-cleft palate. Tex Rep Biol Med 17:637-644.

Webster WS, Brown-Woodman PDC, Snow MD, Danielsson BRG. 1996. Teratogenic potential of almokalant, dofetilide, and $d$-sotalol: drugs with potassium channel blocking activity. Teratology 53:168-175.

Wilson JG. 1965. Methods for administering agents and detecting malformations in experimental animals. In: Wilson JG, Warkany J, editors. Teratology: principles and techniques. Chicago: University of Chicago Press.

Wolpert L, Beddington R, Brockes J, Jessell T, Lawrence P, Meyerowitz E. 1998. Principles of development. London: Current Biology Ltd.

Woolfenden GE. 1961. Postcranial morphology of the waterfowl. Bull Florida State Mus Biol Sci 6:1-129.

Wosskressensky NM. 1928. Über die Wirkung der Röntgenbestrahlung auf das embryonale Wachstum. Arch Entw Mech 113:447-461. 